Original article

\title{
STAND-ALONE PEEK CAGE FOR SINGLE LEVEL CERVICAL DISC DISEASE SHORT TERM RESULTS.
}

\author{
Ahmed Sleem, Mostafa Meshneb \\ Orthopedic Surgery dept., Faculty of Medicine, Sohag Univ., Sohag, Egypt \\ "E-mail: asaleh1975@yahoo.com
}

Received 13/2/2020

Accepted 30/4/2020

\begin{abstract}
The Enthusiasm for Cervical cages in cervical fusion operations is an effort to avoid the morbidity associated with autogenous bone graft harvesting. The goal of the current study was to assess the reliability and efficacy of anterior cervical discectomy and fusion (ACDF) using a PEEK cage filled with hydroxyapatite granules in the treatment of single level disc affection. 19 patients affected by single-level cervical disc disease were included in this study. The clinical findings were assessed according to Odom's criteria at last follow-up. Cervical spine segmental sagittal alignment was evaluated preoperative, direct postoperative and 12 months later. 19 patients underwent ACDF using a PEEK cervical cage. The clinical assessment according to Odom's criteria after 12 months was excellent in 50\%, good in $24 \%$ patients, fair in $11 \%$ and 15 poor clinical results. The mean segmental lordosis before surgery was $2^{\circ}$, corrected to $-6.6^{\circ}$ immediately postoperative. The final mean segmental lordosis was $3.3^{\circ}$; the loss of correction was $3.5^{\circ}$. Anterior cervical discectomy and fusion using a stand-alone PEEK cage can be considered a safe and effective technique for the management of single level cervical disc disease.
\end{abstract}

Keywords: ACDF, PEEK cage, Hydroxyapatite granules

\section{Introduction}

The vast majority of patients with symptomatic cervical disc degeneration (CDD) respond well to conservative treatment. Anterior cervical discectomy and fusion (ACDF) is considered the gold standard for the treatment for non-responders. According to literature, positive predictive to intense radicular pain, low disability, young age, soft disc disease in one segmental level, male sex, non-smoker status, presence of a correlation between radiological and clinical findings, good hand strength, good active range of motion in the neck, and no spinal litigations [1]. However, the classic method of Cloward and Smith and Robinson [2] using an autologous tricortical iliac bone graft has been reported to have documented iliac donor site complications $[3,4]$. These complications include persistent Donor site pains, infection, hematoma formation, iliac crest fracture, and meralgia parasthetica. In order to overcome those problems, ACDF using an intervertebral cage has been used with favorable results. Stand-alone intervertebral cages made of a range of materials such as stainless steel, titanium, carbon fiber and polyetheretherketone (PEEK) $[5,6]$ can be effective for restoring the intervertebral disc height and lordosis, providing load-bearing support to the anterior column and preventing graft 
collapse [5,7]. Polyethere-therketone (PE $\mathrm{EK}$ ) is a non-absorbable biopolymer that has been used in a variety of medical devices. It is biocompatible, radiolucent so easy to assess fusion and has modulus of elasticity similar to the bone (less stress shielding) [8]. Cage stand-alone technology, as presented by Bagby [9], was found on the principle of distraction compression. A sufficiently distracted intervertebral space after discectomy could be stabilized for multidirectional movement by tension forces of residual annulus and ligaments.

\section{Materials and Methods}

A retrospective study of 19 patients with single-level degenerative disc disease between $\mathrm{C} 3$ and $\mathrm{C} 7$ were treated by ACDF using PEEK cages between August 2014 and June 2017. Inclusion criteria include: 1) One or more of the following symptoms and signs of CDD: a. Persistent severe radicular pain not responding to conservative management for three months. b. Cervical radiculopathy with progressive paresis c. Selected cases with myelopathy

\subsection{Surgical procedure}

The anterior approach of Smith and Robinson [2] was used. Cervical discectomy, with decompression of the dura and removal of any osteophytes were performed. The posterior longitudinal ligament was excised to remove disc fragments. Meticulous Curettage of the upper and lower end plates to remove chondral layer with preservation of the subchondral bone was done. The optimal PEEK cage was selected and filled with hydroxyapatite granules (B- OstINbone ${ }^{\circledR}$, Basic Healthcare products Pvt. Ltd), fig. (1). The PEEK cage was impacted into the disc space after

\subsection{Radiological assessment}

Segmental sagittal alignment of instrumented level was adequate measured using a special software (Trauma Cad® - Voyant Health Ltd.) preoperative,
Cages filled up with autologous material, allograft or bone substitute such as demineralized bone matrix or hydroxyapatite granules would resist disc space collapse and should not migrate until fusion occurred, allowing biological bone healing in an incompressible spacer. The purpose of this retrospective study is to evaluate the effectiveness of ACDF using PEEK cages packed with hydroxyapatite granules for single level degenerative cervical disc disease and to present the long-term clinical and radiological outcomes.

secondary to cervical spinal canal stenosis that can be adequately decompressed with ACDF. d. Selected cases with mainly neck pain and headache and less radicular pain. 2) MRI- documented CDD with compression of cervical nerve roots or spinal cord, which most likely explain the clinical symptoms and signs. The exclusion criteria were: a. Cervical trauma within the past four weeks. b. Cervical neoplasia. c. Ongoing cervical infection.

distraction with the use of Caspar distractor. Suction drain was used in all patients and removed 24 hours postoperative. All the patients were discharged on the second day protected by Philadelphia collar for 6 weeks with gradual resumption of the normal daily life thereafter. Plain AP and lateral cervical spine radiographs were taken after surgery and at 3,6 and 12 months post-operatively. Odom's criteria [10] were used to evaluate clinical outcomes of the patients at the $12^{\text {th }}$ month followup visit, tab. (1).

direct postoperative and 6 months postoperatively, fig. (2). A written consent was signed by all patients. 


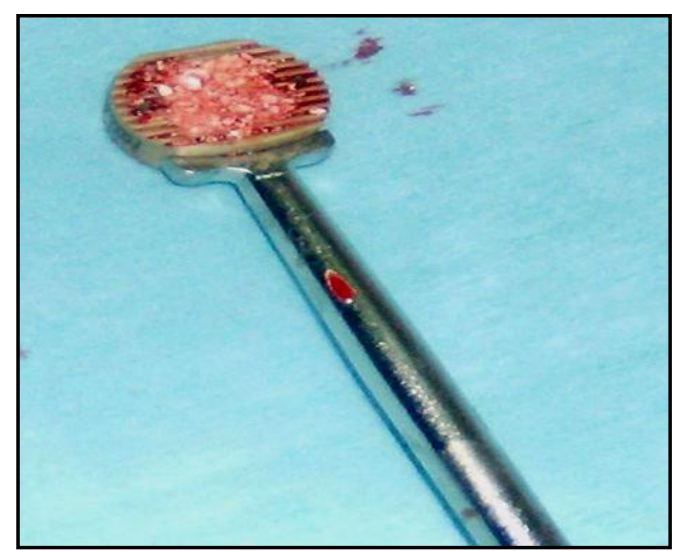

Figure (1) Shows PEEK cage filled with hydroxyapatite granules (B-OstINbone $®$, Basic Healthcare products Pvt. Ltd) and attached to a special holder

Table (1) Classification of outcome according to Odom's criteria

\begin{tabular}{|l|l|}
\hline Excellent & All preoperative symptoms relieved; abnormal findings improved \\
\hline Good & $\begin{array}{l}\text { Minimal persistence of preoperative symptoms; abnormal findings } \\
\text { unchanged or improved }\end{array}$ \\
\hline Fair & $\begin{array}{l}\text { Definite relief of some preoperative symptoms; other symptoms unchanged } \\
\text { or slightly improved }\end{array}$ \\
\hline Poor & Symptoms and signs unchanged or exacerbated \\
\hline
\end{tabular}

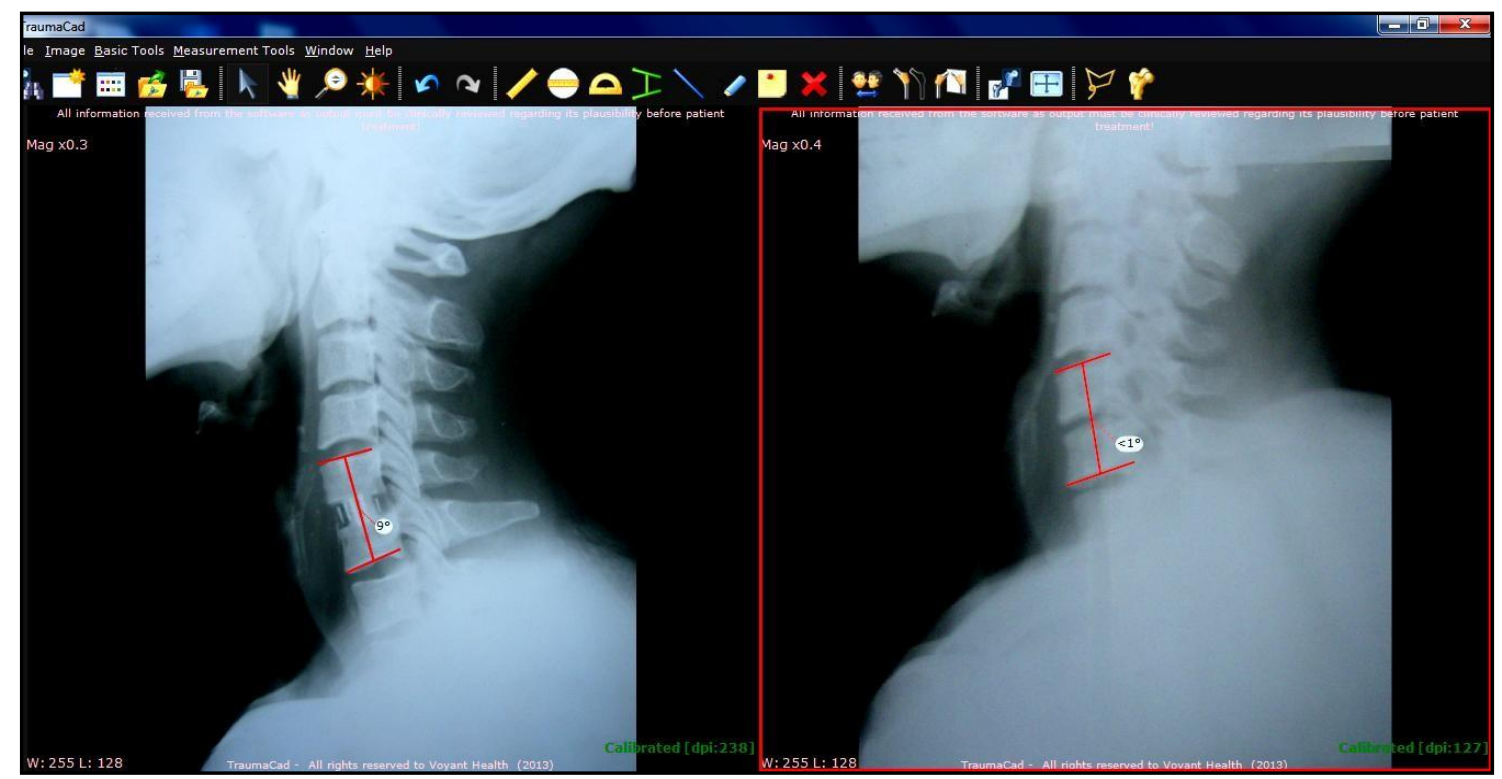

Figure (2) Shows software for measuring Segmental sagittal alignment (SSA) of the instrumented level (TraumaCad® - Voyant Health Ltd.)

\section{Results}

A total of 19 patients ( 9 male, 10 female) with a mean age of 52.9 years (aged between 28 and 68 years) underwent ACDF using PEEK cages filled with hydroxyapatite granules (B- OstINbone ${ }^{\circledR}$, Basic Healthcare products Pvt. Ltd). All the patients were discharged without any com- plications one day after surgery. Odom's criteria were used to assess the patients clinically at the last follow up visit, tab. (1). In this series, the mean operation time was $177.1 \mathrm{~min}$ (range, 67 to $251 \mathrm{~min}$ ), estimated blood loss was below $50 \mathrm{ml}$ in all 19 patients, and the mean hospital stay 
was 3.8 days (range, 2 to 7 days). All patients were followed up at least 1 year (range, 12 to 18 months). C5-6 was the major disc for surgery in this series. The demographic data of patients are shown in tab. (2). All 25 disc interspaces in 19 patients achieved solid union at final followup, fig. (3). Clinical outcomes were rated as excellent or good in 14 patients (success rate: $74 \%$ ). Two patients were graded as fair and three as poor clinical results. The mean pre-operative, immediately post-operative, and final interbody space heights were $5.0 \mathrm{~mm}$ (range, 2.6 to $7.0 \mathrm{~mm}$ ), 7.3 $\mathrm{mm}$ (range, 5.0 to $8.7 \mathrm{~mm}$ ), and $6.2 \mathrm{~mm}$ (range, 4.0 to $8.0 \mathrm{~mm}$ ). The mean collapse of interbody space was $1.1 \mathrm{~mm}$. The mean size of cages used in this series is $6.2 \mathrm{~mm}$ (5-7). Additionally, the mean segmental lordosis before surgery was $2.0^{\circ}$ (range, $-5.2^{\circ}$ to $16.4^{\circ}$ ), corrected to $6.6^{\circ}$ (range, $-3.2^{\circ}$ to $22.1^{\circ}$ ) immediately after surgery. The final mean segmental lordosis was $3.3^{\circ}$ (range, $-9.9^{\circ}$ to $16.1^{\circ}$ ); the loss of correction was $3.3^{\circ}$. In these three patients with poor clinical results, the mean pre-operative interspace height was $4.8 \mathrm{~mm}$. The mean immediately post-operative disc height was $6.4 \mathrm{~mm}$, and the final disc height was $5.7 \mathrm{~mm}$. The loss of disc height was $0.7 \mathrm{~mm}$. The mean segmental lordosis was $-1.6^{\circ}$ before surgery, corrected to $-0.9^{\circ}$ immediately after surgery, and the final Cobbs angle was $-4.4^{\circ}$. The mean loss of lordosis correction was $3.5^{\circ}$. The radiological data are shown in tab. (3). There was no wound infection or further nervous tissue damage during the surgery

Table (2) Patient demographics.

\begin{tabular}{|l|c|}
\hline \multicolumn{1}{|c|}{ Characteristic } & Total $(\mathrm{n}=9)$ \\
\hline $\begin{array}{l}\text { Sex } \\
\text { - Male }\end{array}$ & 9 \\
- Female & 10 \\
\hline Age & $52.9(28-68)$ \\
\hline Radiculopathy & 13 \\
\hline Myelopathy & 2 \\
\hline Radiculomyelopathy & 4 \\
\hline Level & 1 \\
- C 3-4 & 5 \\
- C 4-5 & 11 \\
- C 5-6 & 8 \\
\hline Operation time & $177.1(67-251)$ \\
\hline Hospital stay & $3.8(2-7)$ \\
\hline Blood loss (ml) & $<50$ \\
\hline
\end{tabular}

Table (3): Radiological data.

\begin{tabular}{|l|c|c|c|}
\hline \multicolumn{1}{|c|}{ Parameters } & Total & $\begin{array}{c}\text { Success result } \\
\text { (excellent, good })(\mathbf{n}=\mathbf{1 4})\end{array}$ & $\begin{array}{c}\text { Poor result } \\
(\mathbf{n = 3})\end{array}$ \\
\hline Disc height & 5 & 4.9 & 4.8 \\
- Pre operative & 7.5 & 7.3 & 6.4 \\
- Post operative & 6.2 & 6.6 & 5.7 \\
\hline - Final & 6.2 & 6.5 & 5.8 \\
\hline Cage size ( mm ) & & 1.3 & -1.6 \\
\hline Segmental angle (lordosis angle ) & 2 & 7 & -0.9 \\
- Pre operative & 6.6 & 3.4 & 4.4 \\
- Post operative & 3.3 & & \\
- Final & & & \\
\hline
\end{tabular}




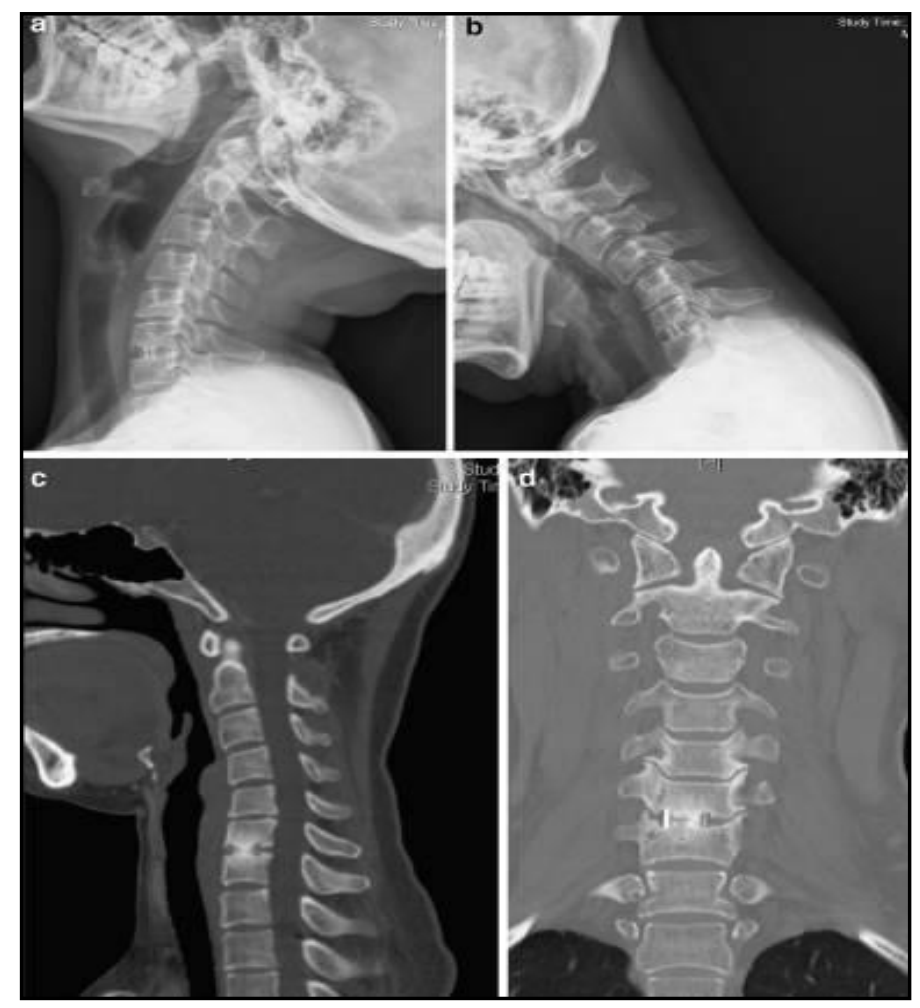

Figure (3) Shows lateral flexion-extension cervical spine radiographs (a-b) and sagittal-coronal CT scans (c-d) obtained 12 months after C6-7 anterior cervical discectomy and fusion. Evidence of solid bridging bone on CT scans and no instability on flexion-extension radiographs were demonstrated

\section{Discussion}

ACDF has become a well- established operative procedure used to treat a variety of cervical spinal disorders. The success of this procedure relies on thorough decompression and development of a solid osseous fusion [11,12]. Although tricortical autograft harvested from iliac crest as interbody fusion material can provide satisfactory clinical results and fusion rates, donor- site complications are around $20 \%$ $[3,8]$. To eliminate autograft-related problems, interbody cages were developed for fusion operations. In clinical practice $[13,14]$, distraction with restoration of disc height in degenerative spine increased intervertebral foraminal volume and contributed to nerve root decompression as measured experimentally. PEEK cages are currently the most preferred. Compared with titanium and carbon fiber cages, PEEK cages are more biocompatible $[15,16]$ and radiolucent, which allows for precise radiological evaluation of bony union. In addition,
PEEK cages are expected to result in lower subsidence rates than that with using metal cages because their modulus of elasticity is similar to that of bone [17] Cho et al. compared the results of 40 patients who underwent ACDF with PEEK spacers filled with autogenous iliac cancellous bone graft and a comparable group who underwent ACDF with autogenous tricortical iliac crest graft [18]. The fusion rate in the PEEK group was $100 \%$, whereas that in the autogenous tricortical iliac crest graft group was $93 \%$. The complication rate was lower in the PEEK cage group. Although clinical results were satisfactory, it was still necessary to create iliac wound even though the wound was small in the PEEK cage group. In our series we packed the cage with hydroxyapatite granules to avoid any donor site morbidity. Sagittal segmental alignment is a good indicator of the efficacy of anterior cervical discectomy and interbody fusion [19]. 
Comparison between preoperative and postoperative SSA demonstrated the efficacy of our technique for correcting cervical sagittal alignment when degenerative changes produce cervical spine straighttening or cervical kyphosis. SSA angles measured at last follow-up demonstrate a slight loss of correction, but these changes were not significant, suggesting that the correction obtained with surgery was mai- ntained. Excellent result in $50 \%$ and good result in $24 \%$ according to Odom's criteria demonstrate that ACDF can be considered a good and effective technique for treating patients suffering from degenerative cervical pathology. The weakness of this study that no control group, small number of patients and short term follow up of patients.

\section{Conclusion}

Anterior cervical discectomy and interbody fusion using PEEK cervical cage and bone graft substitutes can be an effective and low-risk technique with minimal surgical risk and eliminating any donor site morbidity. Long term follow up is needed to assess fusion and subsidence.

\section{References}

[1]Anderson, P., Subach, B., Riew, K. (2009). Predictors of outcome after anterior cervical discectomy and fusion: A multivariate analysis. Spine 34: 161-166

[2]Smith, G., Robinson, R. (1958). The treatment of certain cervical- spine disorders by anterior removal of the intervertebral disc and interbody fusion. J. of Bone and Joint Surgery American. 40-A (3):607-624.

[3]Arrington, E., Smith, W., Chambers, H., et al. (1996). Complications of iliac crest bone graft harvesting. Clinical Orthopaedics and Related Research. 329: 300-309.

[4]Goulet, J., Senunas, L., De Silva, G., et al. (1997). Autogenous iliac crest bone graft. Complications and functional assessment. Clinical Orthopaedics and Related Research. 339: 76-81.

[5]Kast, E., Derakhshani, S., Bothmann, M., et al. (2009). Subsidence after anterior cervical inter-body fusion. A randomized prospective clinical trial. Neurosurgical Review. 32 (2): 207-214

[6]Kulkarni, A., Hee, H., Wong, H. (2007). Solis cage (PEEK) for anterior cervical fusion: Preliminary radiological results with emphasis on fusion and subsidence. J. of the North American Spine Society. 7 (2): 205-209.
[7]Kandziora, F., Pflugmacher, R., Schafer, J., et al. (2001). Biomechanical comparison of cervical spine interbody fusion cages. Spine. 26 (17): 1850- 1857.

[8]Liao, J., Niu, C., Chen, W. et al. (2008). Polyetheretherketone (PEEK) cage filled with cancellous allograft in anterior cervical discectomy and fusion. Int. Orthopaedics. 32 (5): 643-648.

[9] Bagby, G. (1988). Arthrodesis by the distraction-compression method using a stainless steel implant. Orthopedics. 11 (6): 931-934.

[10] Odom, G., Finney, W., Woodhall, B., (1958). Cervical disk lesions. J. of the American Medical Association. 166 (1): 23-28.

[11]Sampath, P., Bendebba, M., Davis, J., et al. (2000). Outcome of patients treated for cervical myelo-pathy: A prospective, multicenter study with independent clinical review. Spine. 25 (6): 670-676.

[12] Vavruch, L., Hedlund, R., Javid, D. et al. (2002). A prospective randomized comparison between the Cloward procedure and a carbon fiber cage in the cervical spine: A clinical and radiologic study. Spine. 27 (16): 1694-1701.

[13]Chen, D., Fay, L., Lok, J., et al. (1995). Increasing neuroforaminal volume by anterior interbody distraction in degenerative lumbar spine. Spine. 20 (1): 74-79. 
[14]Colpan, M., Attar, A., Sekerci, Z., et al. (2006). Cervical foraminal area and intervertebral height changes after titanium ring cage placement: preliminary results. J. of Clinical Neuroscience. 13 (2): 228-232.

[15] Murphy, M., Trimble, M., Piedmonte, M., et al. (1994). Changes in the cervical foraminal area after anterior discectomy with and without a graft, Neurosurgery. 34 (1): 93-96.

[16] Toth, J., Wang, M., Estes, B., et al. (2006). Polyetheretherketone as a biomaterial for spinal applications, Biomaterials. 27 (3): 324-34.

[17]Wenz, L., Merritt, K., Brown, S., et al.
(1990). In vitro biocompatibility of polyetherether-ketone and polysulfone composites. J. of Biomedical Materials Research. 24 (2): 207-215.

[18]Cho, D., Liau, W., Lee, W., et al. (2002). Preliminary experience using a polyetheretherk-etone (PEEK) cage in the treatment of cervical disc disease. Neurosurgery. 51 (6): 1343-1349.

[19]Faldini, C., Pagkrati, S., Leonetti, D., et al. (2011). Sagittal segmental alignment as predictor of adjacentlevel degeneration after a cloward procedure. Clinical Orthopaedics and Related Research. 469 (3): 674-681. 